Please do not remove this page

RMIT

UNIVERSITY

\title{
Protecting nature on private land using revolving funds: Assessing property suitability
}

Hardy, Mathew; Bekessy, Sarah; Fitzsimons, James; Mata, Luis; Cook, Chris; Nankivell, Alex; Smillie, Kate https://researchrepository.rmit.edu.au/esploro/outputs/9921858832701341/filesAndLinks?institution=61RMIT_INST\&index=null

Hardy, M., Bekessy, S., Fitzsimons, J., Mata, L., Cook, C., Nankivell, A., Smillie, K., \& Gordon, A. (2018).

Protecting nature on private land using revolving funds: Assessing property suitability. Biological

Conservation, 220, 84-93. https://doi.org/10.1016/j.biocon.2018.01.026

Document Version: Accepted Manuscript

Published Version: https://doi.org/10.1016/j.biocon.2018.01.026

Repository homepage: https://researchrepository.rmit.edu.au

(c) 2018 Elsevier Ltd. All rights reserved.

Downloaded On 2023/04/26 22:31:08 +1000 
Thank you for downloading this document from the RMIT Research Repository.

The RMIT Research Repository is an open access database showcasing the research outputs of RMIT University researchers.

RMIT Research Repository: http://researchbank.rmit.edu.au/

\section{Citation:}

Hardy, M, Bekessy, S, Fitzsimons, J, Mata, L, Cook, C, Nankivell, A, Smillie, K and Gordon, A 2018, 'Protecting nature on private land using revolving funds: Assessing property suitability', Biological Conservation, vol. 220, pp. 84-93.

See this record in the RMIT Research Repository at:

https://researchbank.rmit.edu.au/view/rmit:47067

Version: Accepted Manuscript

\section{Copyright Statement:}

(C) 2018. This manuscript version is made available under the CC-BY-NC-ND 4.0 license http://creativecommons.org/licenses/by-nc-nd/4.0/

\section{Link to Published Version:}

https://dx.doi.org/10.1016/j.biocon.2018.01.026 


\section{Protecting nature on private land using revolving funds: 2 Assessing property suitability}

\section{$3 \quad$ Abstract}

$4 \quad$ Protecting biodiversity on private land is an important and growing part of global conservation efforts.

5 Revolving funds are used by conservation organisations to buy, on-sell and permanently protect private

6 land with important ecological values. By reinvesting proceeds from sales in additional properties, revolving

7 funds offer a potentially cost-effective way to protect biodiversity. Their success requires managers to

8 choose properties that can be on-sold and recover costs, with resale outcomes having consequences for

9 subsequent acquisitions. However, revolving fund property selection is a multi-dimensional decision,

10 influenced by various ecological, social and financial considerations. In conjunction with revolving fund managers, we developed a Bayesian Belief Network (BBN) to understand which factors they consider to be the most influential on a property's suitability for acquisition, and how much to pay for it. Sensitivity analysis revealed that managers perceive property suitability to be heavily influenced by the threat to the property's ecological values, the acquisition and ongoing management costs, and finding alternative options for protection. Amenity values were seen to heavily influence property resale. Threat and alternative options influence how much to pay, but most influential was the balance of the fund when the purchasing decision is made. Our results suggest managers are taking a low risk approach to property selection. Opportunities may exist to apply revolving funds to higher risk properties otherwise difficult to conserve, provided the need for resale is still met. Ensuring revolving funds target properties with suitable attributes could increase the contribution of this tool to conserving biodiversity on private land. protected areas 


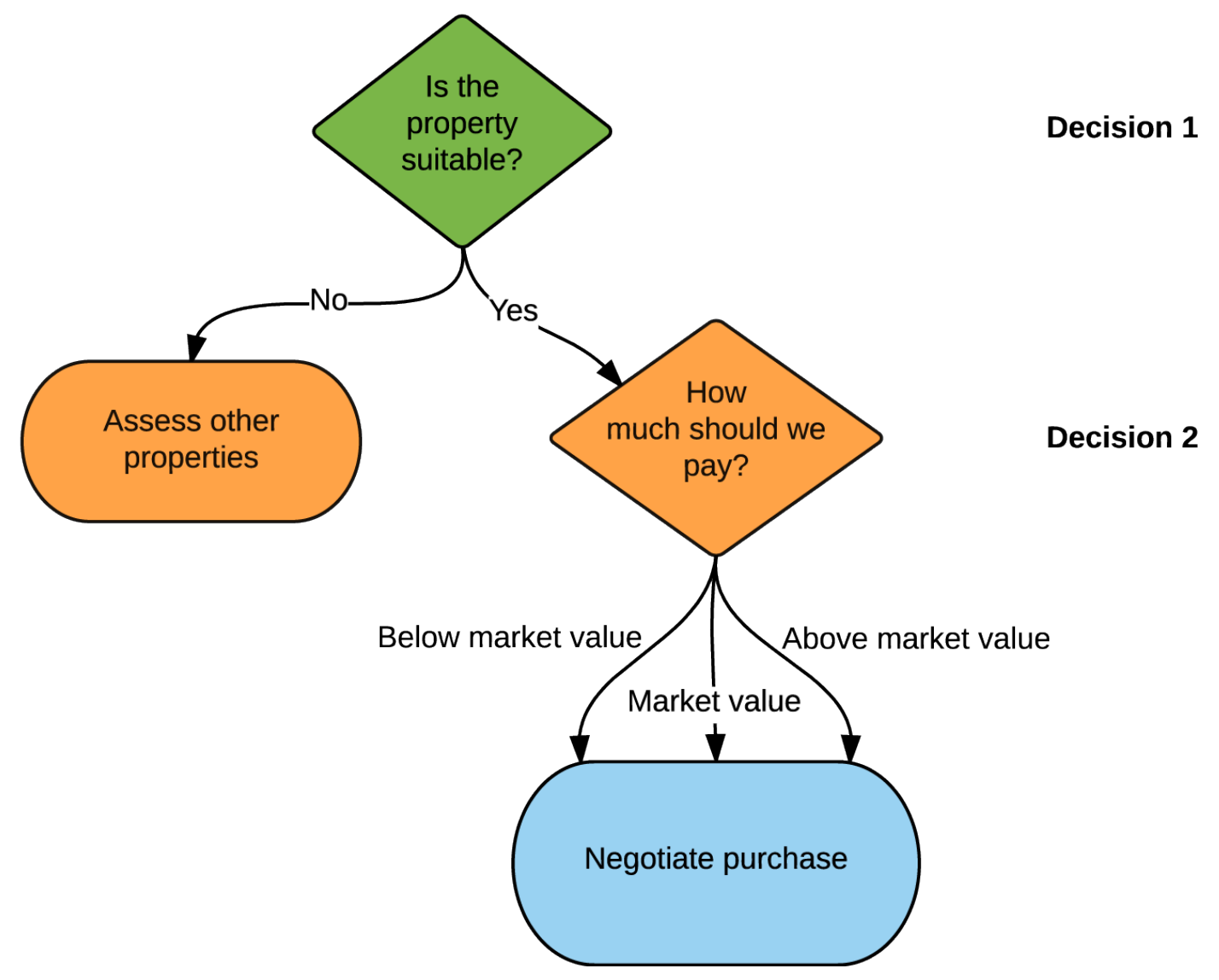




\section{Introduction}

Protecting biodiversity on private land is an important and growing part of global conservation efforts. A number of policy approaches exist to permanently protect private land, some of which can be classified as Privately Protected Areas (PPAs) (Stolton et al., 2014). The dominant approaches currently used include acquisition (whereby private land is acquired and managed for biodiversity by a conservation organisation), and voluntary protection agreements that legally bind landowners to manage their land for biodiversity such as conservation covenants or easements (Kamal et al., 2015).

In some countries, conservation organisations use 'revolving funds' to acquire private land with high conservation value and then on-sell it to new owners, in the process adding an in-perpetuity conservation covenant or easement (Brewer, 2003; Fitzsimons, 2015). The agreement permanently restricts activities harmful to biodiversity, while any proceeds from the sale are re-invested to acquire and protect additional properties, continuing the cycle of protection (Cowell and Williams, 2006). A conceptually simple model, revolving funds provide a potentially cost-effective way to achieve permanent protection by recouping costs through resale. They can be used to intervene in the property market to protect ecological values at a time when properties are under threat of development (Armsworth and Sanchirico, 2008), and are presumably at their most effective when turning over properties with conservation value quickly and maintaining fund capital. The revolving fund approach is similar to acquiring land with conservation value and transferring it to government ownership ('pre-acquisition'), except the new landowner is typically a private party (Brewer, 2003). Revolving funds currently operate in Australia, Canada, Chile and the USA, with a combined capital pool of at least US\$384m, which to date has protected over 684000 hectares (Hardy et al., in review).

A mix of approaches (e.g. acquisition, permanent agreements, non-binding agreements) is thought to be an effective way to implement conservation on private land (Doremus, 2003). Part of ensuring the efficient implementation of the mix involves identifying the situations and properties to which these approaches are best suited. Because of their capacity for continuing reinvestment, revolving funds have a unique and potentially important role in private land conservation, including the protection of land that may not be available via other approaches. Yet decision-making regarding property purchase is highly complex. A first step to helping with more strategic selection of revolving fund properties and increasing their contribution to private land conservation is understanding how decisions are currently made.

\subsection{Revolving fund property selection}

A series of interviews with revolving fund practitioners in Australia revealed a range of influences on property selection, foremost amongst these being the ability to re-sell acquired properties to new owners (Hardy et al., 2017). This work revealed that each potential property has multiple attributes that could affect its suitability for acquisition, with decision variables including: conservation values (e.g. threatened 
species or ecological communities, landscape connectivity); financial values (e.g. purchase price, sale price, likely time to re-sell); and social values (e.g. amenity values such as a house site, visual attractiveness). However, the process of evaluating these attributes can be resource-intensive for conservation organisations, and in general, the relative importance of these attributes, and how they interact to impact on suitability for revolving funds has received little research attention.

Beyond suitability, revolving fund managers face a second multi-dimensional decision over how much to pay for any given property. Acquiring conservation properties can require large capital investments, leading to difficult decisions amidst fluctuations in the property market (McDonald-Madden et al., 2008). Revolving fund programs would benefit considerably from purchasing at or below market value, but the willingness of landholders to sell can vary (Winter et al., 2005). Beyond purchase, managers need to consider the money likely to be returned to the fund upon resale ("resale price"), accounting for any change in land value that might result from adding a permanent conservation easement or covenant, which can vary considerably between properties (Anderson and Weinhold, 2008). There is uncertainty over the time it will take to onsell the property ("resale time") (Armsworth and Sanchirico, 2008), where long resale times can tie up capital and impact future purchases. Also relevant are the management costs whilst the property is in the organisation's possession (Hunter and Kohring, 2009), and the costs of providing ongoing stewardship support for landholders after resale (Adams et al., 2012). Finally, acquisition decisions often have to be made rapidly when properties appear on the open market (Fitzsimons and Looker, 2012).

Probabilistic reasoning approaches to decision-making, such as Bayesian Belief Networks (BBNs), can be useful for these complex, uncertain problems. BBNs provide a structured way to integrate limited and disparate information sources, including both quantitative and qualitative information, and are useful for modelling systems characterised by inherent uncertainty (Aalders, 2008). They have been used to understand a range of conservation issues (see Aguilera et al., 2011), including the identification of suitable areas for conservation and development to avoid conflict (McCloskey et al., 2011), landholder participation in conservation (Torabi et al., 2016) and guiding reserve system acquisitions (Schapaugh and Tyre, 2012). Here we apply the BBN approach to assessing the suitability of properties for revolving fund purchase, based on current decision-making.

\subsection{Revolving fund property selection in Australia}

In Australia, there are five major revolving fund programs of various sizes operated by land trusts (Table 1), with the broadly similar purpose of increasing the amount of private land protected by conservation covenants. They operate in similar ways: identifying, assessing and purchasing private freehold land in rural landscapes with high conservation value, before then on-selling it with the condition that the new owners enter into an in-perpetuity conservation covenant. The programs typically focus on lifestyle properties and in some programs, agricultural properties with conservation values. Before purchase, staff assess a 
property's suitability, negotiate a purchase price, and then make a recommendation to a board or governing committee who make the final purchasing decision. Often properties initially identified are not purchased, either because they are found unsuitable (ecologically or financially), or because they are sold before negotiations are finalised. Collectively, these programs have protected 164 properties covering almost 150000 hectares (Table 1). The similarity in operations between these programs, the number of properties revolved and area protected, as well as the breadth of operations, provides an opportunity to draw on the collective expertise of managers and gain insights into what makes a property suitable for the revolving fund approach.

Table 1. Key statistics for the major revolving fund programs currently operating in Australia*.

\begin{tabular}{|c|c|c|c|c|c|}
\hline Organisation & Australian State & $\begin{array}{l}\text { Years } \\
\text { operating }\end{array}$ & $\begin{array}{l}\text { Total fund size } \\
\text { (AUD approx.) }\end{array}$ & $\begin{array}{l}\text { Properties } \\
\text { "revolved" }\end{array}$ & $\begin{array}{l}\text { Area protected } \\
\text { (hectares) }\end{array}$ \\
\hline $\begin{array}{l}\text { Nature Conservation Trust of } \\
\text { NSW }\end{array}$ & New South Wales & 15 & $\$ 10 m$ & 34 & 23,424 \\
\hline Queensland Trust for Nature & Queensland & 13 & $\$ 7 m$ & 17 & 104,000 \\
\hline Nature Foundation SA & South Australia & 15 & $\$ 1.4 \mathrm{~m}$ & 28 & 12,242 \\
\hline Tasmanian Land Conservancy & Tasmania & 13 & $\$ 6.5 m$ & 28 & 2,928 \\
\hline \multirow[t]{2}{*}{ Trust for Nature (Victoria) } & Victoria & 28 & $\$ 4 m$ & 57 & 6,852 \\
\hline & & Total & $\$ 28.9 m$ & 164 & 149,446 \\
\hline
\end{tabular}

\footnotetext{
* As of June 2017
}

Using the experience of revolving fund managers in Australia, we built a probabilistic reasoning model (a Bayesian Belief Network) to integrate and systematically explore the factors relevant to revolving fund property selection. From this model based on managers' reasoning we sought to answer: i) how do decision factors interact to affect the suitability of a property for purchase?; ii) which factors do managers consider to be most influential on property suitability?; and iii) which factors are most influential on how much managers are willing to pay for a given property? Understanding how decision-making happens can facilitate critical analysis of the strategies that are used, and furthermore generates an opportunity to explore current approaches with the view to increasing the efficacy of revolving fund programs.

\section{Material and methods}

\subsection{Bayesian Belief Networks}

A BBN is a directed acyclic graphical representation of a system that can be used to examine a network of interactions between different variables (Chen and Pollino, 2012). BBNs consist of parent and child nodes that represent important variables in a system, with related nodes connected by links (Aalders, 2008; Korb and Nicholson, 2011). Each node has a set of 'states', representing categories of values within the variable. 
The interaction between nodes is defined using Conditional Probability Tables (CPTs), which are set for each child node and define how the child node responds to changes in probabilities of the parent node/s states. Once the BBN has been defined, users can enter quantitative or qualitative information ('evidence') into the parent nodes, then assess how that evidence changes the probability distribution of the child node/s of interest. To provide greater clarity over the network structure in this study, hereafter we refer to 'input' nodes as those earliest in the chain, 'intermediate' nodes as those internal to the network, and 'decision' nodes as those at the final point in the chain capturing summary information from the network relevant to decision-making.

\subsection{Conceptual model}

We built an initial conceptual BBN model (Chen and Pollino, 2012) of the revolving fund property selection decision in Netica (Norsys 1992-2014) based on an influence diagram developed from interviews with revolving fund managers (Hardy et al., 2017). This conceptual BBN model contained the main factors that managers had identified in those interviews as being influential in property suitability.

\subsection{Revising, parameterising and assessing the model}

We held a one-day workshop in July 2015 with practitioners from the five major revolving fund programs currently operating in Australia. The practitioners were selected due to their experience and knowledge of revolving fund operations, and had previously participated in semi-structured interviews about revolving fund property selection (Hardy et al., 2017). Whilst practitioners from each major Australian program were invited, only three were able to attend.

The context for the workshop was a common revolving fund property assessment problem. Practitioners were asked to assume they had a list of potential properties that had already been through initial checks (e.g. size, price, location) and were considered to be worth protecting (i.e. met covenanting criteria). The workshop was aimed at eliciting how managers combine all relevant information to make two primary decisions: 1) whether or not to recommend a property for purchase, and 2) how much to pay for it. Participants were shown the initial conceptual BBN model and invited to discuss its components and structure as a group. They were then asked to draw on their collective experience to refine the nodes, links and structure of the network to make a generalised model, including the addition or removal of factors. During the process, some intermediate nodes were added to assist with the conceptualisation of the decision and the elicitation of the CPTs. Following the guidance of Marcot (2006), we kept the number of parent nodes for any single child node to three or less, and the number of node states and model layers to five or less. Once the model structure was finalised, for each node participants identified the node state categories (all having three, e.g. low, medium and high) and relevant values (e.g. presence of threatened species or ecological communities). 
We then elicited the values of the CPTs for the intermediate and decision nodes from participants. For each of these nodes, each participant was handed a worksheet containing an empty CPT to fill in individually, resulting in three independently parameterised BBNs with identical node structures ('final workshop $\left.B B N s^{\prime}\right)$. Following this, we conducted a live preliminary interrogation of the BBN to explore how the 'Property suitability' and 'How much to pay' nodes were affected by selecting different property attributes, checking that the model produced results representing the participants' beliefs.

Following the workshop, we migrated the BBN into the R statistical environment v3.0.2 (R Core Team, 2016), using the gRain (Højsgaard, 2012) and gRbase (Dethlefsen and Højsgaard, 2005) packages. We created a single consensus BBN model using the structure from the final workshop BBNs, and populated its CPTs using the mean of the CPT values elicited from each participant during the workshop.

\subsection{Sensitivity analysis}

We undertook a global sensitivity analysis of the consensus BBN, to assess the relative influence of each of the model factors on the 'Property suitability' and 'How much to pay' nodes. We randomly allocated probability values to the states of each input node in the BBN (for details see Supplementary Materials) and recorded the resulting probability values for each of the intermediate and decision nodes. We then compared the randomised network results to those of the neutral network (i.e. that with equal probability values for all input node states). The comparison was done by calculating the distances between the high and low values for all nodes, where:

$$
\text { Distance }=\sqrt{\left(H_{b}-H_{g}\right)^{2}+\left(M_{b}-M_{g}\right)^{2}+\left(L_{b}-L_{g}\right)^{2}}
$$

and $H$ is the value of the 'high' state in the node, $M$ is the value of the 'medium' state in the node and $L$ is the value of the 'low' state in the node. The subscript $b$ represents the value in the neutral network, and the subscript $g$ represents the sampled values in each realisation of the global sensitivity analysis.

We ran the sensitivity analysis 10000 times, in each run recording the distance values for all nodes, and afterwards standardised the distance values across all model runs. Setting each of the intermediate and decision node distances in turn as the dependent variable, and all input node distances as independent variables, we then fitted linear regressions to each of the dependent variables using the same set of independent variables. The resulting coefficient values were then used as an indicator of the relative influence (or 'sensitivity') of each input node on the intermediate and decision nodes, with greater values of the regression coefficient indicating a greater influence.

\subsection{Scenario evaluation}

Following the sensitivity analysis, we used a range of four predefined property types as scenarios to explore the interaction between conservation and property resale. The property types were defined by varying the 
conservation and resale characteristics to create best and worst-case property scenarios, as well as mixed

183 cases of low conservation values and high resale prospects, and high conservation values and low resale 184 prospects. The input node states used for each scenario are provided as Supplementary Material (Table 185 A1).

\section{Results}

\subsection{The consensus Bayesian Belief Network}

188 The consensus BBN model is composed of 16 nodes, nine of which are input nodes, five are intermediate 189 nodes, and two are decision nodes (Figure 1). The node names, types, states and descriptions are provided 190 in Table 2. Managers linked property suitability directly to its conservation value, its financial impact on the 191 fund, and the likelihood of protecting it through other (non-revolving fund) approaches. A property's conservation value was derived from its on-site ecological values (e.g. presence of threatened species and/or communities), landscape values (e.g. connectivity and additions to the protected area network), and the threat to the persistence of these ecological values (e.g. from residential/agricultural/commercial development). A property's financial value to the fund was determined by its ability to be on-sold, here represented by its expected resale time and resale price, as well as the anticipated costs of acquisition and ongoing management (e.g. maintenance). Resale time and price were linked to the property's marketability, itself consisting of the site's amenity values (e.g. the availability of utilities, a house site, aesthetic appeal), community context values (e.g. proximity to local town, schools) and market conditions (e.g. increasing or decreasing activity in the local real estate market). The question of how much to pay was linked directly to the suitability of a property, but also to the amount of money currently available in the fund (account balance). 


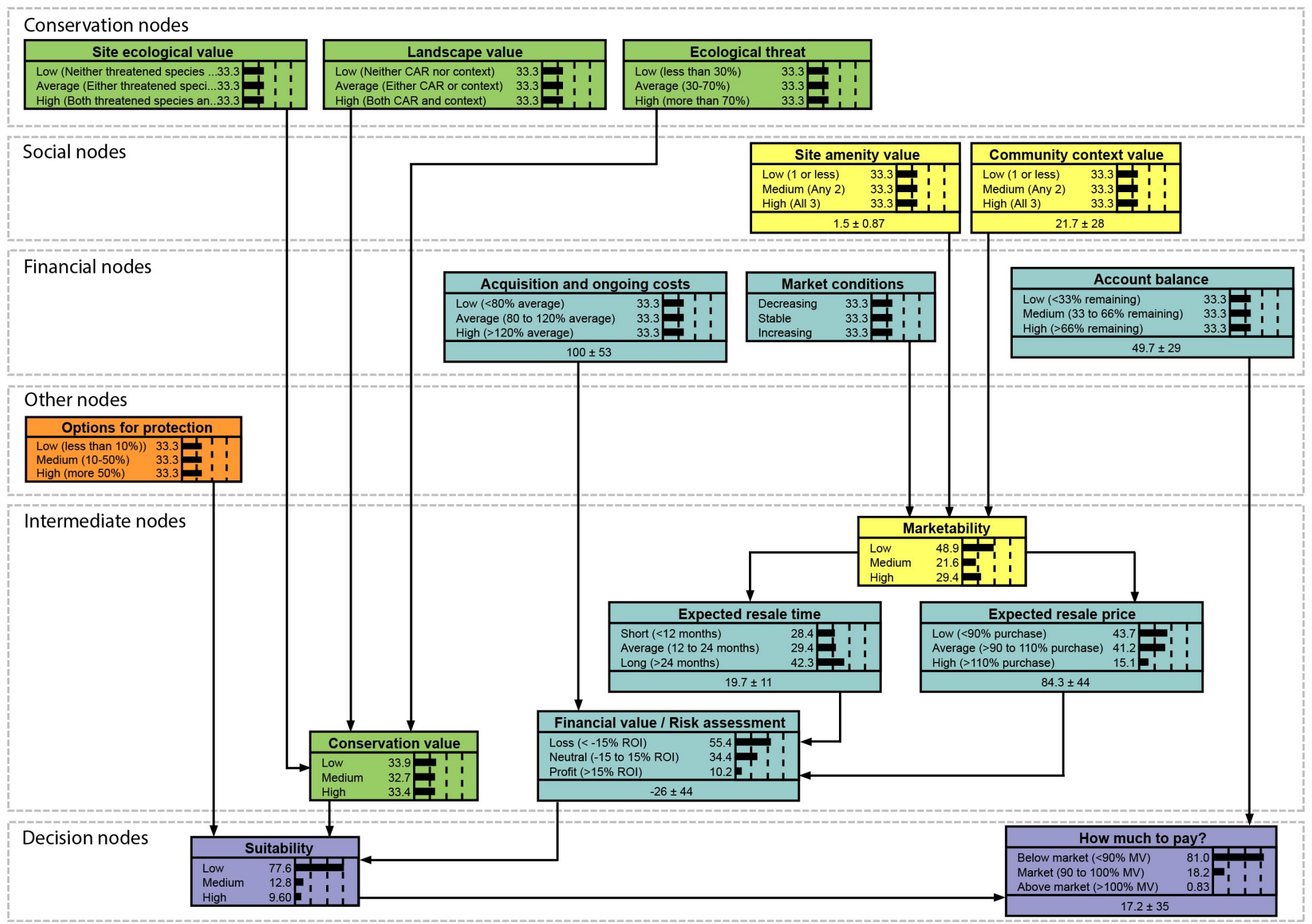


Table 2. Description of nodes in the BBN model of revolving fund property selection

\begin{tabular}{|c|c|c|c|c|}
\hline Node & Type & Description & BBN states & State description \\
\hline $\begin{array}{l}\text { Site } \\
\text { ecological } \\
\text { value }\end{array}$ & Input & $\begin{array}{l}\text { A measure of the ecological } \\
\text { values present on the site, } \\
\text { represented by: the presence } \\
\text { of threatened species or } \\
\text { ecological communities }\end{array}$ & Medium & $\begin{array}{l}\text { No presence of threatened species or communities } \\
\text { Presence of either threatened species or } \\
\text { communities } \\
\text { Presence of both threatened species and } \\
\text { communities }\end{array}$ \\
\hline $\begin{array}{l}\text { Landscape } \\
\text { value }\end{array}$ & Input & $\begin{array}{l}\text { A measure of the property's } \\
\text { landscape conservation values, } \\
\text { represented by: the property's } \\
\text { contribution to enhancing the } \\
\text { comprehensiveness, adequacy, } \\
\text { or representativeness (CAR) of } \\
\text { the protected area network, or } \\
\text { its broader landscape context } \\
\text { values (e.g. connectivity, } \\
\text { buffering of protected areas } \\
\text { etc.) }\end{array}$ & Medium & $\begin{array}{l}\text { Meets both CAR criteria and landscape context } \\
\text { values }\end{array}$ \\
\hline $\begin{array}{l}\text { Ecological } \\
\text { threat }\end{array}$ & Input & $\begin{array}{l}\text { An estimate of the threat the } \\
\text { property is under (e.g. from } \\
\text { residential, agricultural or } \\
\text { commercial development, land } \\
\text { use change) }\end{array}$ & High & $\begin{array}{l}\text { Less than } 30 \% \text { chance that the property's ecological } \\
\text { values will be lost } \\
30-70 \% \text { chance that the property's ecological values } \\
\text { will be lost } \\
\text { Greater than } 70 \% \text { chance that the property's } \\
\text { ecological values will be lost }\end{array}$ \\
\hline $\begin{array}{l}\text { Conservation } \\
\text { value }\end{array}$ & $\begin{array}{l}\text { Interme } \\
\text { diate }\end{array}$ & $\begin{array}{l}\text { An aggregate node, providing } \\
\text { an overall estimate of the } \\
\text { property's conservation value }\end{array}$ & $\begin{array}{l}\text { Medium } \\
\text { High }\end{array}$ & $\begin{array}{l}\text { Property has low conservation value } \\
\text { Property has medium conservation value } \\
\text { Property has high conservation value }\end{array}$ \\
\hline $\begin{array}{l}\text { Acquisition } \\
\text { and ongoing } \\
\text { costs }\end{array}$ & Input & $\begin{array}{l}\text { An estimate of the costs of } \\
\text { purchasing the property and its } \\
\text { ongoing management for the } \\
\text { conservation organisation, } \\
\text { relative to other revolving fund } \\
\text { properties }\end{array}$ & $\begin{array}{l}\text { Low } \\
\text { Average } \\
\text { High }\end{array}$ & $\begin{array}{l}\text { Costs are less than } 80 \% \text { of average } \\
\text { Costs are } 80-120 \% \text { of average } \\
\text { Costs are greater than } 120 \% \text { of average }\end{array}$ \\
\hline $\begin{array}{l}\text { Expected } \\
\text { resale time }\end{array}$ & $\begin{array}{l}\text { Interme } \\
\text { diate }\end{array}$ & $\begin{array}{l}\text { An estimate of the time it will } \\
\text { take to on-sell the property }\end{array}$ & $\begin{array}{l}\text { Short } \\
\text { Average } \\
\text { Long }\end{array}$ & $\begin{array}{l}\text { Less than } 12 \text { months } \\
\text { 12-24 months } \\
\text { Longer than } 24 \text { months }\end{array}$ \\
\hline Expected & Interme & An estimate of the price at & Low & Less than $90 \%$ of purchase costs \\
\hline
\end{tabular}




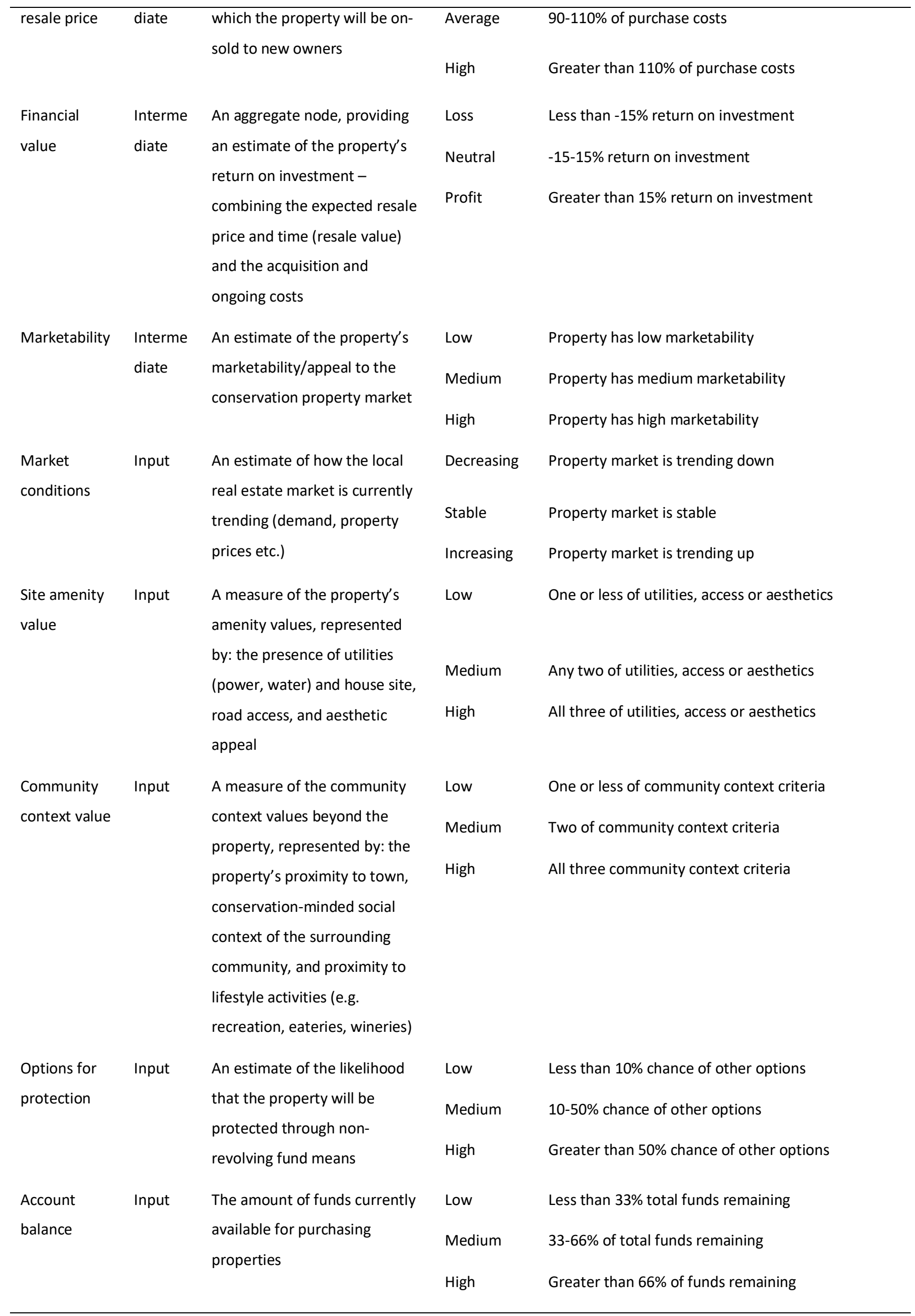




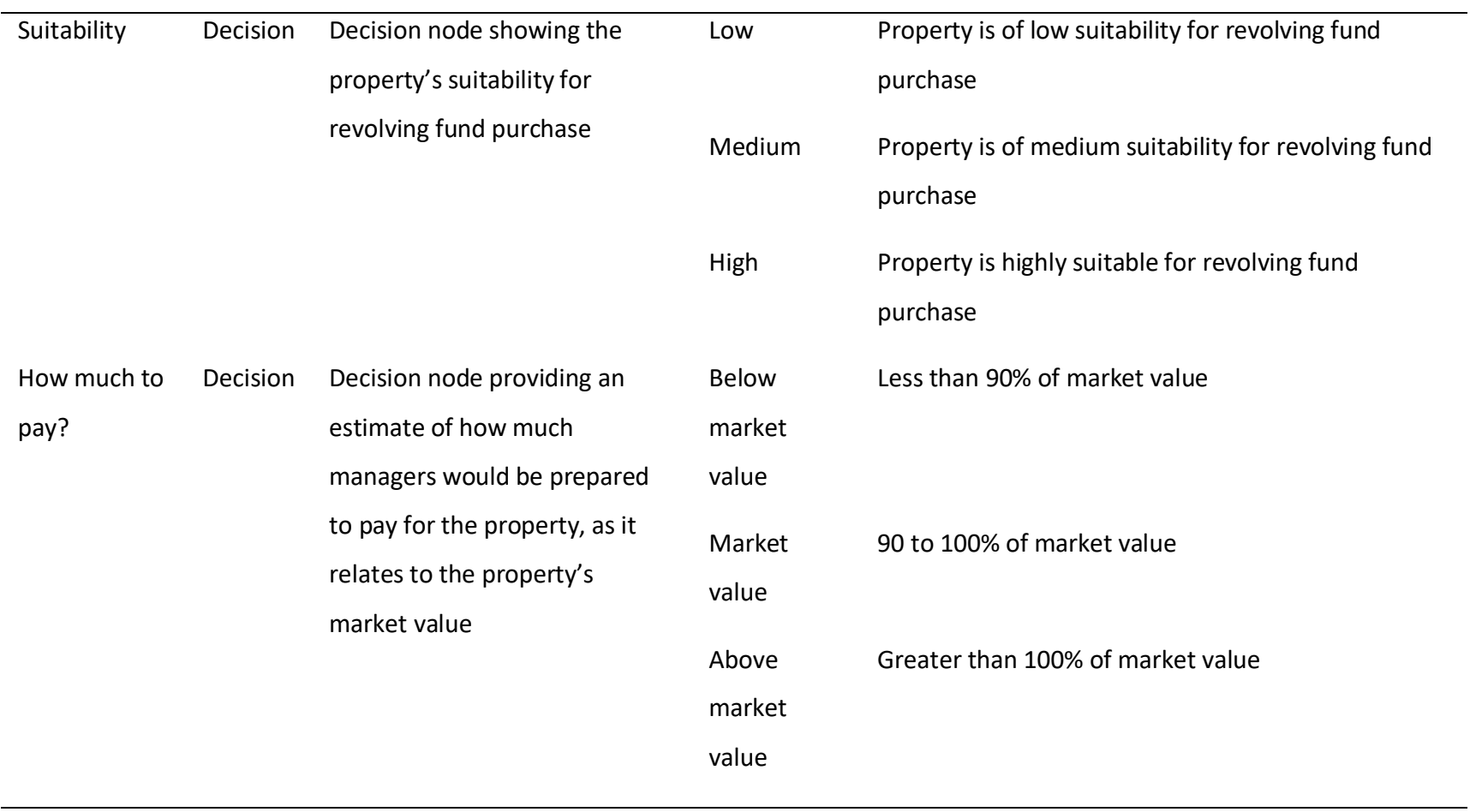

\subsection{Sensitivity analysis results}

The results of the global sensitivity analysis for the decision nodes are shown in Figure 3. The x-axis shows the value of the coefficient estimates associated with the regression undertaken as part of the sensitivity analysis (see methods). Larger values indicate nodes with greater influence. Looking at input nodes only, for suitability (Figure 3a) the three nodes with the greatest influence were ecological threat, options for protection, and acquisition and ongoing costs, respectively. In general, the results showed a diminishing influence of nodes with distance from the decision node, therefore the nodes

215 in Figures $3 \mathrm{a}$ and $3 \mathrm{~b}$ are grouped together by their distance from the decision nodes (e.g. two layers back, 216 three layers back) to facilitate comparison of sensitivity at equal distances. Restricting to just the nodes two layers away from suitability, ecological threat had by far the greatest influence, double that of acquisition and ongoing costs, and more than three times that of landscape value. The top three input nodes influencing the how much to pay node (Figure $3 b$ ) were account balance (with by far the greatest influence, more than all other nodes combined, but it is also the closest input node), followed by ecological threat (three layers back) and other options for protection (two layers back). Restricting to nodes three layers away, ecological threat had twice the influence of landscape value, and 3.5 times the influence of acquisition and ongoing costs. 
a)

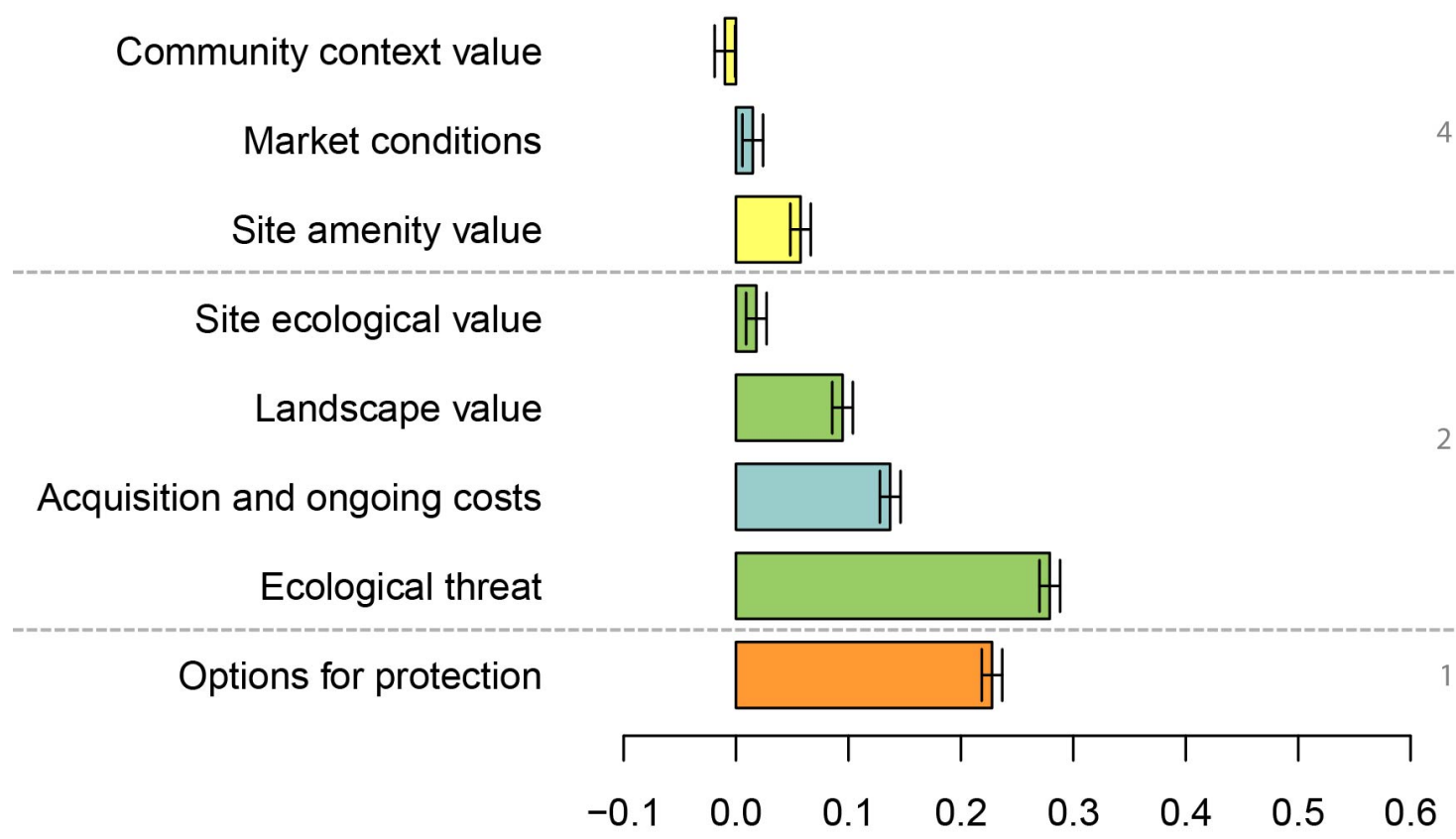

Regression coefficient

b)

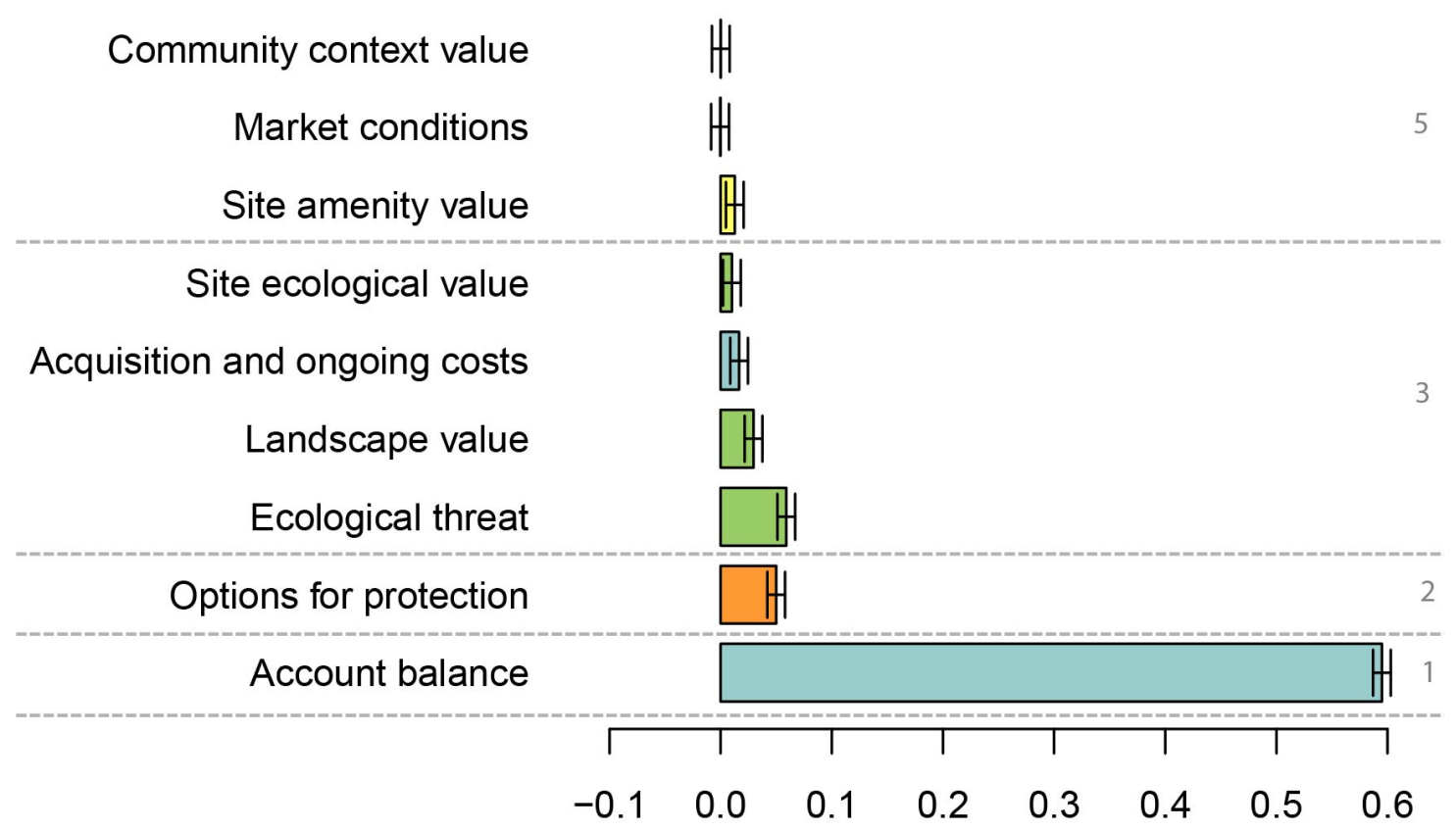

Regression coefficient

Figure 2. Barplots of the sensitivity analysis for a) suitability node and b) how much to pay node. Bars show the coefficient estimates from the linear regression, for input nodes above the decision nodes. Larger bars indicate greater influence, and error bars show standard errors on the coefficient estimates. Dashed lines separate nodes at different layers, and grey numbers indicate the number of layers away the input node is from the decision node. Nodes at 3 layers (a) and 4 layers (b) above are not shown because they are intermediate nodes.

For the intermediate conservation value node, ecological threat was by far the most influential input node, almost 2.5 times the influence of landscape and site ecological values combined (Figure 4a). Site ecological values had by far the smallest relative influence on conservation value. For financial value (Figure 4b), the acquisition and ongoing costs node had by far the greatest influence, more than three times that of the 
next largest influence (site amenity value), although the acquisition and ongoing costs node is only one layer away. The influence of market conditions and community context value was less than a fifth of that 230 from site amenity values.

231 The ability to re-sell the property is central to property selection. For resale time and resale price, looking at 232 the input nodes two layers away (Figure $4 \mathrm{c}$ and $4 \mathrm{~d}$ ), site amenity was by far the most influential for both of 233 these nodes, more than 4.5 times the influence of market conditions and community context value 234 combined.

a)

a) Site ecological value

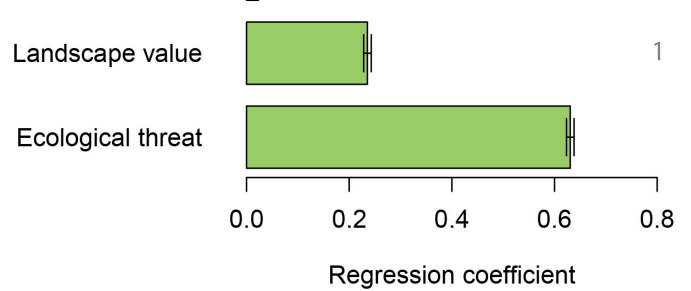

c)

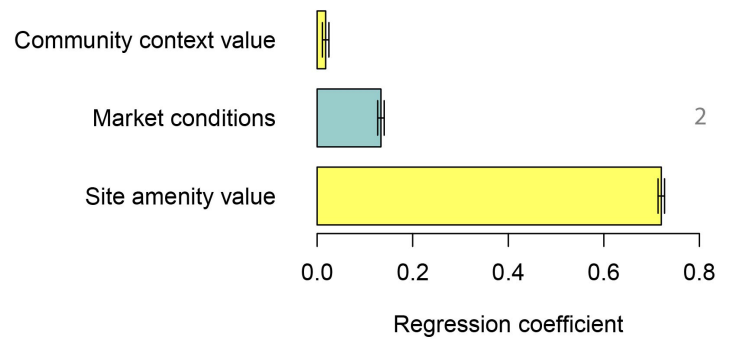

b)

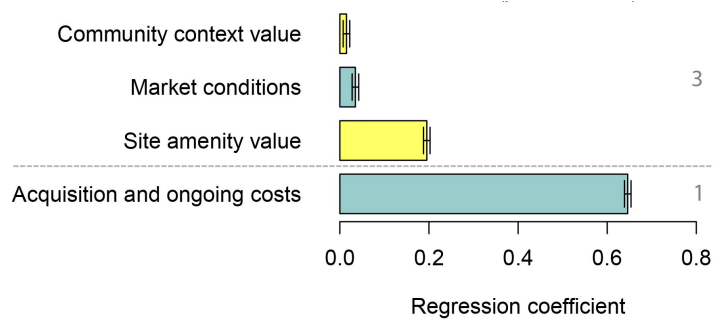

d)

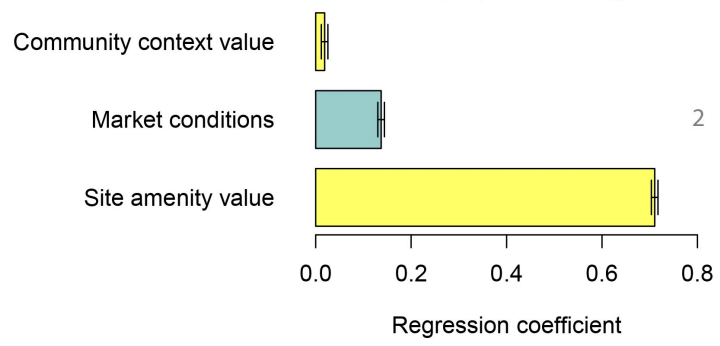

Figure 3. Barplots of the sensitivity analysis for the a) conservation value node, b) financial value node, c) resale time node and e) resale price node. Bars show the co-efficient estimates from the linear regression. Larger bars indicate greater influence, and error bars show standard errors. The dashed line separates nodes at different layers, with grey numbers indicating the number of layers away from the financial value node. Nodes at 2 layers (b) and 1 layer (c and d) above are not shown because they are intermediate nodes.

\subsection{Scenario evaluation results}

The scenario evaluation (Table 3) showed that the most suitable property, according to managers' beliefs, had high conservation values and high resale prospects ('Best-case'), whereas that least suitable had low conservation values and low resale prospects ('Worst-case'). The suitability of a property with low conservation value and high resale prospects ('Mixed-case 2') was not far behind the Worst-case, with a high likelihood of low suitability. A property with high conservation value, but low resale prospects ('Mixedcase $1^{\prime}$ ), showed a high likelihood of low to medium suitability.

Across all property types the scenario evaluation showed that managers would most likely pay at or below market value, though if the properties are of high suitability ('Best-case' and 'Mixed-case 1') there is a small likelihood that managers might consider paying above market value. Properties with low suitability ('Worstcase' and 'Mixed-case 2') would unlikely be pursued, and correspondingly showed no likelihood of managers paying above market value. 
Table 3. Scenario evaluation of the expected suitability for potential revolving fund properties, and how much to pay for them, using the consensus BBN. The probabilities of the decision nodes being in each of the three states given for each scenario.

\begin{tabular}{|c|c|c|c|c|c|c|}
\hline \multirow[b]{2}{*}{ Property scenario } & \multicolumn{3}{|c|}{ Probability of suitability } & \multicolumn{3}{|c|}{ Probability of how much to pay } \\
\hline & Low & Medium & High & $\begin{array}{c}\text { Below market } \\
\text { value }\end{array}$ & $\begin{array}{l}\text { At market } \\
\text { value }\end{array}$ & $\begin{array}{c}\text { Above market } \\
\text { value }\end{array}$ \\
\hline $\begin{array}{l}\text { Best-case (high conservation } \\
\text { value, high resale prospects) }\end{array}$ & 8.8 & 19.8 & 71.4 & 36.5 & 53.5 & 9.98 \\
\hline $\begin{array}{l}\text { Worst-case (low conservation } \\
\text { value, low resale prospects) }\end{array}$ & 99.5 & 0.4 & 0.13 & 99.9 & 0.1 & 0 \\
\hline $\begin{array}{l}\text { Mixed-case } 1 \text { (high } \\
\text { conservation value, low resale } \\
\text { prospects) }\end{array}$ & 56.4 & 32.3 & 11.3 & 64.7 & 31.3 & 4.01 \\
\hline $\begin{array}{l}\text { Mixed-case } 2 \text { (low } \\
\text { conservation value, high resale } \\
\text { prospects) }\end{array}$ & 86.2 & 9.74 & 4.03 & 97.2 & 2.81 & 0 \\
\hline
\end{tabular}

\section{Discussion}

Choosing appropriate properties is central to the ongoing efficacy of revolving funds, and amongst the many properties available that managers can purchase, only some are suitable. The suitability of a property is made up of multiple factors, including ecological and financial characteristics. Using the experience of practitioners, we developed a probabilistic reasoning model to systematically step through the revolving fund property selection problem and identify the factors they believe to be the most influential on property suitability. The model suggests that broadly, managers consider suitable properties to be those with high conservation value and: i) where the resale price is likely to be similar to the purchase, management and transaction costs associated with revolving the property; ii) under high threat and a low likelihood of being protected through other means; and iii) with a high likelihood of resale (particularly in areas of high amenity value). The model also provides a structured and transparent way to examine trade-offs between these factors. With a focus on improving the operation of revolving funds, we use the findings of the model to: i) discuss current decision-making around property suitability, ii) explore the potential limitations of current thinking, and iii) develop guidance for revolving fund programs to assist in property selection.

\subsection{Current decision-making}

The model showed the clear importance to managers of the financial impact that each property transaction will likely have on the fund. This is evidenced through the influence of costs, account balance and resale factors, relating to decisions on both property suitability and how much to pay (Figure 2; Table 3). Managers were particularly focussed on properties with low acquisition and ongoing management costs, 
including those incurred whilst the property is held by the organisation, and the costs of providing support to the landowner once on-sold. Given the common objective for these programs of ongoing fund sustainability, and their ability to continue purchasing additional land being driven by the cumulative financial impact of individual purchases, the focus on low cost properties is unsurprising. Whilst cost is also important for other types of conservation acquisition decisions (e.g. Adams et al., 2012; Carwardine et al., 2008), for revolving fund managers the focus is largely on the financial impact after resale, specifically how much of the costs incurred are covered by the resale price. In many cases this would be very difficult to predict before purchase, and the uncertainty likely leads managers to select properties with low investment risk; highlighting a bias towards properties with a high likelihood of recouping costs. Whilst providing greater certainty over fund sustainability, this likely limits the pool of properties to choose from, for example those that can be purchased at or below market value, where the impact of a restrictive covenant on resale price will be low, and in regions with stable or increasing property prices.

On the ecological side, the model highlights the importance managers place on protecting properties under threat (Figure 3a). Properties under threat (e.g. from commercial, residential or agricultural development) with a low likelihood of being protected through other means were considered to be of higher suitability, and the scenario evaluation suggested managers may consider paying more for these properties (Table 3). For the programs involved in this study, properties need to hold high conservation value in order to meet the required protection standards of a conservation covenant (and thus be considered for purchase), predominantly relating to the existence of high quality remnant ecological values. The managers' emphasis on threat suggests they are using revolving funds to intervene in the property market and protect properties at risk of losing their ecological values, a risk that can be higher under a new owner (Whelan, 1997). Threat would also provide a way for managers to prioritise amongst the multiple properties available for purchase at any one time. The focus on threat and remnant ecological values also explains why managers might perceive a property to be of higher suitability if it is unlikely to be protected through other means (Figure 2), such as voluntary permanent protection agreements (e.g. covenants), direct acquisition and holding (Parker, 2004), or pre-acquisition and transfer to government (Hunter and Kohring, 2009). The model also shows the likelihood of a property being on-sold as a dominant focus for managers when determining suitability (represented in the model as resale time and resale price; Figure 1). The focus on resale is to be expected given that the conservation gains made by revolving funds are driven in large part by property turnover. Site amenity was shown in the sensitivity analysis as the primary influence on resale (Figure $3 c$ and d), which managers had linked to three specific property attributes: utilities, road access and aesthetics. These attributes highlight the importance managers place on the social dimension of revolving fund properties, and aligns with their preference for properties with multiple values beyond conservation; for example, the potential for a dwelling and areas suitable for hobby farming (Hardy et al., 2017). 
other decision factors (e.g. conservation value, ecological threat and financial impact; Figure 2a). This may be due to the structure of the model constraining their influence (n.b. in the final workshop and consensus models the social nodes were furthest from the decision nodes). Nonetheless, social factors are likely key contributors to revolving fund property resale (Hardy et al., 2017), and in conjunction with the focus on remnant conservation values and threat, the preference for properties with amenity values would greatly limit the number of properties seen as suitable for purchase.

\subsection{Limitations and implications of current decision-making}

Whilst contributing to the ongoing sustainability of revolving funds, the emphasis on low investment risk and financial impact, threat to remnant ecological values, and resale may be precluding the purchase of otherwise suitable conservation properties. This includes properties with high conservation values that are difficult to conserve through other means, but have the potential to diminish fund capital. For instance, properties in agricultural areas provide some of the greatest opportunities for private land conservation (Fischer et al., 2012), where the shift to productive land uses threatens remnant ecological values. The high land values in these areas often prohibit acquisition without resale, while landholders may be less likely to enter into permanent conservation agreements (Moon and Cocklin, 2011). Similarly, opportunities may exist in peri-urban areas to protect priority properties at risk of development. The challenge here is that properties of high vulnerability and quality (i.e. under threat) can be more expensive (Newburn et al., 2005), coupled with the potential for a restrictive protection agreement to lower resale values. However, even with some financial losses on individual properties, revolving funds could still provide a cost-effective approach to protecting priority properties in these areas, due to their ability to resell and offset the high acquisition costs - an opportunity often unavailable to other conservation approaches. This could be particularly useful for agricultural properties where only a relatively small proportion of the property requires protection. In peri-urban areas, high amenity values could assist resale, and conservation properties may even attract price premiums from prospective buyers (Hannum et al., 2012). Whilst some programs already actively consider these types of properties, it is likely that even with resale some are simply too expensive (Merenlender et al., 2009). The relative efficiency of using revolving funds in these areas compared to other conservation approaches needs further research.

The focus on resale might also mean acquisition opportunities are excluded where properties may be difficult to on-sell (e.g. due to limited amenity values). With some exceptions, the dominant focus for programs in this study is on properties attractive to lifestyle amenity buyers (e.g. see Cooke and Lane, 2015), in part because of the likely faster resale times. Yet the ability to use revolving funds proactively in the real estate market (Whelan, 1997) to protect strategic conservation assets beyond lifestyle properties is worth considering. There may be other markets that managers can leverage - even if extended resale times are likely. For example, there may be benefit in purchasing a remote property containing an internationally significant wetland important for migratory species, with low amenity values and a limited number of 
potential buyers, but unlikely to receive protection through other means. In this case, extended resale times would be likely and managers may need to dedicate considerable time and effort to find a suitable buyer, maintain flexibility in the terms or timing of the sale (e.g. if a community group needs to raise the funds to acquire the property), and cover management costs in the interim (Armsworth et al., 2011). There would also be a major risk of tying up fund capital if a buyer cannot be found. Whilst some of this risk could be reduced by assessing demand in advance of purchase (e.g. via surveys, market analysis and talking to partners), the risk involved suggests that this use would only be worth considering for extremely high priority properties available below market value (e.g. 'Mixed-case 1', Table 3), or by funds with large amounts of capital. A large fund, relative to the cost of conservation properties, would provide flexibility to acquire this type of property whilst the remainder of the fund focuses on properties with faster turnover (i.e. a portfolio approach), but there would be less capacity for this in small funds. This opportunity notwithstanding, the need for eventual resale means that properties with a very low likelihood of resale are unlikely to be suitable for revolving fund acquisition.

There may also be opportunities to protect properties with high conservation value but low remnant ecological value. For example, a property may hold high amenity values, but be in poor ecological condition and have high potential for restoration, providing an important extension to the habitat of a highly threatened species. In this situation revolving funds could help deliver substantial conservation gains, but managers would need to factor in the costs of restoration (Evans et al., 2015) and ongoing management to the organisation whilst the property is held, and to the new owner once the property is on-sold. The need for restoration could impede resale, particularly if the property's current state means it has low aesthetic values, or will require substantial time or financial investment from the new owners. Additional financial and technical support may be required to increase the capacity and motivation of the new owners to continue restoration activities (Selinske et al., 2015). Whilst it is unlikely that the resale price would be sufficient to cover all restoration and management costs, some costs could be reduced by negotiating assistance from partner organisations (e.g. restoration specialists), or wherever possible, restricting this approach to properties available well below market value. The result may still be cost-effective compared with other approaches, especially where partnerships can be leveraged. The extent to which revolving funds can contribute to the restoration of properties with strategic conservation value remains worthy of further exploration.

\subsection{Developing guidance for revolving fund property selection}

Drawing from the current thinking of managers as captured here in the BBN, and the potential opportunities for conservation that revolving funds might provide, the following guidance is proposed to assist managers in their search for suitable properties. 
1. Set clear strategic conservation priorities to target. Priorities will be program-specific, but may include, for example, protecting threatened species or regions under-represented in reserve systems. Programs may look to prioritise properties in high-threat areas (Byrd et al., 2009), potentially using predictors of habitat conversion to agricultural use (Stephens et al., 2008) and/or basic economic and demographic information (Radeloff et al., 2012) to predict future development and land use patterns.

2. Establish clear guidelines on the characteristics that make a property suitable for purchase. These would likely be a mix of characteristics, including the priority conservation values, estimates of acquisition and management costs (whilst held, and once on-sold), social values (e.g. amenity and community context values) and also estimates of resale factors (e.g. maximum resale time, minimum resale price). The BBN approach presented in this study could be used to identify these characteristics. Ideally the guidelines would be accompanied by an adaptive decision-making process, using resale experience to help reduce uncertainty (see for example Johnson et al. (2007)). The guidelines should also support the manager's need to turn down properties if they are not suitable.

3. Identify regions where the supply and demand for conservation properties overlaps with conservation priorities. Using conservation priorities, property characteristics, and real estate market data, programs could identify regions with a supply of properties suitable to revolving funds. Managers could assess the willingness of landholders to sell (Knight et al., 2011), either via direct approach or surveys, which may also work to reduce acquisition costs. For demand, the historic and potential buyers of revolving fund properties could be surveyed to understand what motivates the purchasing decision, high quality data on the local real estate market could be obtained (Armsworth and Sanchirico, 2008), and regular updates about conservation properties could be sought from agents and property valuers.

4. Establish clear guidelines to help identify how much to pay for properties, and in what circumstances to accept a financial loss. Based on the experience of programs in this study, often managers will aim to pay at or below market value to reduce the financial risk. In some instances, however, managers may need to consider re-selling at a price below costs to secure high priority properties. Setting clear criteria defining the circumstances under which to accept a resale price lower than purchase price plus costs would be beneficial. For example, where the loss on resale is likely more efficient than using alternative conservation approaches.

5. Develop strong partnerships with other conservation organisations. Partner organisations could help identify potential properties and buyers, and assist with ecological restoration and management. This would help identify which properties revolving funds can best help conserve in landscape conservation strategies alongside alternative protection mechanisms (Bode et al., 2011). 


\section{Conclusions}

409 Revolving funds are part of a mix of approaches available in private land conservation and offer an

410 alternative to acquisition for holding (with associated ongoing management) or voluntary permanent

411 conservation agreements. The ability to re-invest proceeds from sales offers unique potential, and selecting

412 appropriate properties that can be on-sold is central to their effectiveness. We have developed a structured

413 probabilistic reasoning model of property suitability, using the experience of revolving fund managers, to

414 better understand the relative influence of the multiple decision factors and help identify which properties

415 might be most suitable. The results suggest that in their assessments of property suitability, managers show

416 preference for properties with low investment risk. This likely limits how revolving funds are currently

417 applied, and there may be other applications where revolving funds could contribute to conservation (some

418 of which are explored above) that warrant further investigation. In other contexts, the main influences on

419 suitability may differ from those here, and the BBN process provides a useful framework for identifying the

420 characteristics of suitable properties. Ensuring revolving fund acquisitions target properties with suitability

421 attributes could help programs reduce the number of properties to assess and allow more efficient

422 implementation of this tool, allowing other approaches to focus on other types of properties and

423 facilitating a more efficient and effective approach to conservation of important private land. 


\section{Acknowledgements}

425 This research was supported by the Australian Research Council's Centre of Excellence for Environmental 426 Decisions, the Australian Government's National Environmental Science Programme - Threatened Species 427 Hub and RMIT University. SB was supported by an ARC Future Fellowship and LM by the National 428 Environmental Science Programme - Clean Air and Urban Landscapes Hub. Maria Plancarte Fexas assisted 429 with the development of Figure 1. Anna Backstrom helped facilitate the workshop where much of the data 430 for this paper was elicited. The authors would like to thank the revolving fund programs Trust for Nature 431 (Victoria), Nature Foundation SA and the Nature Conservation Trust of New South Wales for supporting this 432 research and the decision workshop, and Queensland Trust for Nature and the Tasmanian Land 433 Conservancy for prior and subsequent discussions. Ethics approval through RMIT University DSC CHEAN A 434 Project No. 0000019426-05/15. 


\section{References}

Aalders, I., 2008. Modeling land-use decision behavior with Bayesian Belief Networks. Ecol. Soc. 13, 16.

Adams, V.M., Pressey, R.L., Stoeckl, N., 2012. Estimating land and conservation management costs: The first step in designing a stewardship program for the Northern Territory. Biol. Conserv. 148, 44-53. doi:10.1016/j.biocon.2012.01.064

Aguilera, P.A., Fernández, A., Fernández, R., Rumí, R., Salmerón, A., 2011. Bayesian networks in environmental modelling. Environ. Model. Softw. 26, 1376-1388. doi:10.1016/j.envsoft.2011.06.004

Anderson, K., Weinhold, D., 2008. Valuing future development rights: The costs of conservation easements. Ecol. Econ. 68, 437-446. doi:10.1016/j.ecolecon.2008.04.015

Armsworth, P.R., Cantú-Salazar, L., Parnell, M., Davies, Z.G., Stoneman, R., 2011. Management costs for small protected areas and economies of scale in habitat conservation. Biol. Conserv. 144, 423-429. doi:10.1016/j.biocon.2010.09.026

Armsworth, P.R., Sanchirico, J.N., 2008. The effectiveness of buying easements as a conservation strategy. Conserv. Lett. 1, 182-189. doi:10.1111/j.1755-263X.2008.00028.x

Bode, M., Probert, W., Turner, W.R., Wilson, K.A., Venter, O., 2011. Conservation planning with multiple organizations and objectives. Conserv. Biol. 25, 295-304. doi:10.1111/j.1523-1739.2010.01610.x

Brewer, R., 2003. Conservancy: The land trust movement in America. University Press of New England, Hanover and London.

Byrd, K.B., Rissman, A.R., Merenlender, A.M., 2009. Impacts of conservation easements for threat abatement and fire management in a rural oak woodland landscape. Landsc. Urban Plan. 92, 106-116. doi:10.1016/j.landurbplan.2009.03.003

Carwardine, J., Wilson, K.A., Watts, M., Etter, A., Klein, C.J., Possingham, H.P., 2008. Avoiding Costly Conservation Mistakes: The Importance of Defining Actions and Costs in Spatial Priority Setting. PLoS One 3, e2586. doi:10.1371/journal.pone.0002586

Chen, S.H., Pollino, C.A., 2012. Good practice in Bayesian network modelling. Environ. Model. Softw. 37, 134-145. doi:10.1016/j.envsoft.2012.03.012

Cooke, B., Lane, R., 2015. How do amenity migrants learn to be environmental stewards of rural landscapes? Landsc. Urban Plan. 134, 43-52. doi:10.1016/j.landurbplan.2014.10.006

Cowell, S., Williams, C., 2006. Conservation through buyer-diversity: A key role for not-for-profit landholding organizations in Australia. Ecol. Manag. Restor. 7, 5-21. doi:10.1111/j1442-8903.2006.00242.x

Dethlefsen, C., Højsgaard, S., 2005. A common platform for graphical models in R: The gRbase package. J. Stat. Softw. 14, 1-12. doi:10.1002/dev.20059

Doremus, H., 2003. A policy portfolio approach to biodiversity protection on private lands. Environ. Sci. Policy 6, 217-232. doi:10.1016/S1462-9011(03)00036-4

Evans, M.C., Tulloch, A.I.T., Law, E.A., Raiter, K.G., Possingham, H.P., Wilson, K.A., 2015. Clear consideration of costs, condition and conservation benefits yields better planning outcomes. Biol. Conserv. 191, 716-727. doi:10.1016/j.biocon.2015.08.023

Fischer, J., Hartel, T., Kuemmerle, T., 2012. Conservation policy in traditional farming landscapes. Conserv. Lett. 5, 167-175. doi:10.1111/j.1755-263X.2012.00227.x

Fitzsimons, J.A., 2015. Private protected areas in Australia: current status and future directions. Nat. Conserv. 10, 1-23. doi:10.3897/natureconservation.10.8739 
Fitzsimons, J., Looker, M., 2012. Innovative approaches to land acquisition and conservation management: the case of Fish River Station, Northern Territory, in: Figgis, P., Fitzsimons, J., Irving, J. (Eds.), Innovation for 21st Century Conservation. Australian Committee for IUCN, Sydney, pp. 78-85.

Hannum, C., Laposa, S., Reed, S.E., Pejchar, L., Ex, L., 2012. Comparative analysis of housing in conservation developments: Colorado case studies. J. Sustain. Real Estate 4, 149-176.

Hardy, M.J., Fitzsimons, J.A., Bekessy, S.A., Gordon, A., 2017. Factors influencing property selection for conservation revolving funds. Conserv. Biol. in press. doi:10.1111/cobi.12991

Hardy, M.J., Fitzsimons, J.A., Bekessy, S.A., Gordon, A., in review. Purchase, conserve, repeat: A review of using revolving funds to conserve private land.

Højsgaard, S., 2012. Graphical Independence Networks with the gRain Package for R. J. Stat. Softw. 46, 126.

Hunter, L., Kohring, M., 2009. Preacquisitions, in: Bates, S. (Ed.), Selling and Transferring Land and Conservation Easements. Land Trust Alliance, Washington DC, pp. 135-156.

Johnson, K.H., Benefield, J.D., Wiley, J.A., 2007. The probability of sale for residential real estate. J. Hous. Res. 16, 131-142.

Kamal, S., Grodzinska-Jurczak, M., Brown, G., 2015. Conservation on private land: a review of global strategies with a proposed classification system. J. Environ. Plan. Manag. 58, 576-597. doi:10.1080/09640568.2013.875463

Knight, A.T., Grantham, H.S., Smith, R.J., McGregor, G.K., Possingham, H.P., Cowling, R.M., 2011. Land managers' willingness-to-sell defines conservation opportunity for protected area expansion. Biol. Conserv. 144, 2623-2630. doi:10.1016/j.biocon.2011.07.013

Korb, K., Nicholson, A., 2011. Bayesian Artificial Intelligence. CRC Press, London.

Marcot, B.G., Steventon, J.D., Sutherland, G.D., McCann, R.K., 2006. Guidelines for developing and updating Bayesian belief networks applied to ecological modeling and conservation. Can. J. For. Res. 36, 30633074. doi:10.1139/X06-135

McCloskey, J.T., Lilieholm, R.J., Cronan, C., 2011. Using Bayesian belief networks to identify potential compatibilities and conflicts between development and landscape conservation. Landsc. Urban Plan. 101, 190-203. doi:10.1016/j.landurbplan.2011.02.011

McDonald-Madden, E., Bode, M., Game, E.T., Grantham, H., Possingham, H.P., 2008. The need for speed: Informed land acquisitions for conservation in a dynamic property market. Ecol. Lett. 11, 1169-77. doi:10.1111/j.1461-0248.2008.01226.x

Merenlender, A.M., Newburn, D., Reed, S.E., Rissman, A.R., 2009. The importance of incorporating threat for efficient targeting and evaluation of conservation investments. Conserv. Lett. 2, 240-241. doi:10.1111/j.1755-263X.2009.00073.x

Moon, K., Cocklin, C., 2011. Participation in biodiversity conservation: Motivations and barriers of Australian landholders. J. Rural Stud. 27, 331-342. doi:10.1016/j.jrurstud.2011.04.001

Newburn, D., Reed, S., Berck, P., Merenlender, A., 2005. Economics and land-use change in prioritizing private land conservation. Conserv. Biol. 19, 1411-1420. doi:10.1111/j.1523-1739.2005.00199.x

Parker, D.P., 2004. Land trusts and the choice to conserve land with full ownership or conservation easements. Nat. Resour. J. 44, 483-518.

R Core Team, 2016. R: A language and environment for statistical computing. 
Radeloff, V.C., Nelson, E.J., Plantinga, A., Lewis, D.J., Helmers, D.P., Lawler, J.J., Withey, J., Beaudry, F., Martinuzzi, S., Butsic, V. a., Lonsdorf, E. V., White, D., Polasky, S., 2012. Economic-based projections of future land use in the conterminous U.S. under alternative economic policy scenarios. Ecol. Appl. 22, 1036-1049. doi:10.1890/11-0306.1

Schapaugh, A.W., Tyre, A.J., 2012. Bayesian networks and the quest for reserve adequacy. Biol. Conserv. 152, 178-186. doi:10.1016/j.biocon.2012.03.014

Selinske, M.J., Coetzee, J., Purnell, K., Knight, A.T., 2015. Understanding the motivations, satisfaction, and retention of landowners in private land conservation programs. Conserv. Lett. 8, 282-289. doi:10.1111/conl.12154

Stephens, S.E., Walker, J.A., Blunck, D.R., Jayaraman, A., Naugle, D.E., Ringelman, J.K., Smith, A.J., 2008. Predicting risk of habitat conversion in native temperate grasslands. Conserv. Biol. 22, 1320-1330. doi:10.1111/j.1523-1739.2008.01022.x

Stolton, S., Redford, K.H., Dudley, N., 2014. The futures of privately protected areas. IUCN, Gland, Switzerland.

Torabi, N., Mata, L., Gordon, A., Garrard, G., Wescott, W., Dettmann, P., Bekessy, S.A., 2016. The money or the trees: What drives landholders' participation in biodiverse carbon plantings? Glob. Ecol. Conserv. 7, 1-11. doi:10.1016/j.gecco.2016.03.008

Whelan, B.R., 1997. The advantages of a trust in conservation for private land owners, in: Hale, P., Lamb, D. (Eds.), Conservation Outside Nature Reserves. Centre for Conservation Biology, The University of Queensland, Brisbane, pp. 190-195.

Winter, S.J., Esler, K.J., Kidd, M., 2005. An index to measure the conservation attitudes of landowners towards Overberg Coastal Renosterveld, a critically endangered vegetation type in the Cape Floral Kingdom, South Africa. Biol. Conserv. 126, 383-394. doi:10.1016/j.biocon.2005.06.015 